To appear in: M. C. Galavotti, S. Hartmann, M. Weber, W. Gonzalez, D. Dieks, and T. Uebel, eds., New Directions in the Philosophy of Science. Springer.

\title{
Confessions of a Complexity Skeptic
}

Raphael Scholl

\begin{abstract}
Three objections to Max Urchs's paper on complexity are discussed. First, Urchs's macroeconomic illustrations of the benefits of complexity thinking are open to more conventional interpretations. Second, Urchs formulates a thesis concerning the relationship between science and society which is untenable if taken as a historical claim and insufficiently developed if taken as a metaphor. Third, methodological problems in history and philosophy of science plague Urchs's discussion of neuroscience.
\end{abstract}

\section{Introduction}

Max Urchs argues in his contribution to the present volume that scientists and philosophers of science should be more mindful of complexity. In this he agrees with a number of recent contributions by such authors as Melanie Mitchell (2009a) and Sandra Mitchell (2009b). In her book Unsimple Truths, Sandra Mitchell argues that progress in scientific understanding will increasingly require complexity thinking, and that the philosophy of science will need to adjust its meta-reflections accordingly. Mitchell thinks that a host of issues will have to be reconsidered: reduction and emergence, lawfulness, scientific method, prediction, and policy analysis.

In his discussion of cases from economics and the neurosciences, Urchs touches on many of the same issues. In the comments in hand, it is not my goal to engage with the debate about complexity as a whole. Instead I will focus on objections in three of Urchs's main areas of discussion: economic markets, the changing legacy of the scientific revolution, and neuroscience. I am particularly interested in the

Raphael Scholl

University of Bern, History and Philosophy of Science, Institute of Philosophy, Länggassstr. 49a, CH-3012 Bern, Switzerland

e-mail: raphael.scholl@gmail.com 
question of what we can learn from individual cases from the sciences - that is, on the proper use of case studies in philosophy of science.

First, Urchs argues that complexity thinking is helpful in modern economics, and he identifies John Maynard Keynes as an early exponent of this view. I will argue that a close consideration of Keynes's science should not leave us unambiguously favorable to complexity thinking. Second, Urchs makes the historical claim that a certain kind of relationship between science and society was established during the scientific revolution, and that this will have to change to accommodate complexity thinking. I will argue that the historical claim is difficult to maintain, and that the changing relationship between science and society is, at the very least, still up for debate. Third, Urchs discusses the neurosciences as an area where complexity thinking will potentially be helpful. I neither affirm nor reject the thesis, but I argue that the neurosciences as a case study are not suitable for Urchs's purposes on strictly methodological grounds.

It will be useful for the rest of the discussion to have some idea of what is meant by complexity (for a recent discussion, see references cited above and Ladyman et al, 2012). There is no consensus answer, and Urchs's own approach to delineating the phenomenon is rather impressionistic. For the present discussion, I will think of complex systems as involving a) a large number of entities, b) a large number of possible (although perhaps simple) interactions, and c) multiple relevant levels of description. The system at the aggregate level will display some sort of organization or adaptation, and it may moreover be subject to continuing evolution, such that the entities or their interactions change over time. I take it that these features roughly capture the systems that authors like Sandra Mitchell and Melanie Mitchell are talking about, and such systems would allow the occurrence of many of the phenomena that Urchs attributes to complex systems (among these are deterministic chaos, non-linearity, surpris $\mathrm{D}^{1}$ and unpredictability).

\section{Keynes, Complexity, and the Ineffectiveness of Monetary Policy During the Economic Crisis}

\subsection{Keynes on parts and wholes}

Urchs argues that John Maynard Keynes must be understood as a precursor of complexity thinking. He quotes from the preface of the French edition of The General Theory of Employment, Interest and Money of 1939:

\footnotetext{
"I argue that important mistakes have been made through extending to the system as a whole conclusions which have been correctly arrived at in respect of a part of it taken in isolation." (Keynes 1973a p. xxxii)
}

\footnotetext{
${ }^{1}$ Unlike Urchs, however, I would strongly caution against a definition of complexity in which subjective psychological experiences such as surprise play a role.
} 
Urchs wants us to read this in the context of complexity - perhaps as an endorsement of system-level emergence. But we must take a close look at what Keynes had in mind here. I will argue that Keynes can be reinterpreted in terms that do not unambiguously support complexity thinking ${ }^{2}$

Keynes's goal in the French preface is to delineate the main distinguishing features of his approach to economic theory, and in particular the reasons why he speaks of a "general theory". Immediately before the quotation above, he writes:

"I have called my theory a general theory. I mean by this that I am chiefly concerned with the behaviour of the economic system as a whole,- -with aggregate incomes, aggregate profits, aggregate output, aggregate employment, aggregate investment, aggregate saving rather than with the incomes, profits, output, employment, investment and saving of particular industries, firms or individuals." (p. xxxii)

This aggregate-level description laid the foundation for the current division of economics into micro- and macroeconomics. Keynes goes on to illustrate the approach using an example. His theory says that for the economy as a whole, savings must equal investment. Now, if taken as a statement about individual economic actors, this is plainly false, since there is no reason why an individual actor's investment should bear any relationship to his or her savings:

\begin{abstract}
"Quite legitimately we regard an individual's income as independent of what he himself consumes and invests. But this, I have to point out, should not have led us to overlook the fact that the demand arising out of the consumption and investment of one individual is the source of the incomes of other individuals, so that incomes in general are not independent, quite the contrary, of the disposition of individuals to spend and invest; and since in turn the readiness of individuals to spend and invest depends on their incomes, a relationship is set up between aggregate savings and aggregate investment which can be very easily shown, beyond any possibility of reasonable dispute, to be of exact and necessary equality." (p. xxxii-Xxxiii)
\end{abstract}

Keynes regards this as a "banale conclusion" with interesting consequences. It follows, for example, that when faced with a large burden of debt, the rational course of action for an individual company is not the same as for an entire national economy. An individual company deals with debt by increasing the ratio of income to expenditures. However, if an entire national economy cuts its spending, then - because one person's spending is another person's income - everybody will be poorer off. Keynes writes:

"[I]t becomes evident that an increased propensity to save will ceteris paribus contract incomes and output; while an increased inducement to invest will expand them." (p. xxxiii)

That increased savings can lead to a loss of wealth is sometimes referred to as "the paradox of thrift". It constitutes the minimal core of recent disputes about how to deal with the economic crisis that started in 2008. Proponents of "stimulus" argue that cutting government spending would be counterproductive, since increased government savings will, as Keynes said, "contract incomes and output" of private

\footnotetext{
${ }^{2}$ Urchs also gives us quotations from Keynes's Treatise on Probability (1973b), and I have no comments to make about these. I agree that it would be worthwhile to read the Treatise on Probability from the point of view of complexity.
} 
actors like firms and households. Proponents of "austerity" argue that nations with too much debt must decrease spending to bring their budgets into balance, and that increased government spending would be ineffective stimulus ${ }^{3}$

Thus aware of the context of Keynes's statement about the properties of parts and wholes, should we read his remark in the context of the debates about complexity? I don't think so, for a much more pedestrian story suggests itself. It seems that Keynes's subdiscipline-founding breakthrough was to identify a successful aggregate-level (as opposed to component-level) description of causal factors in a national economy. His description in terms of aggregate incomes, outputs, profits, and so on, was successful in the sense that robust causal relationships could be identified among these aggregate causal factors, and in the sense that these causal relationships could be used to explain interesting phenomena (such as the behavior of economies in times of recession). The next section's more thorough discussion of the $I S-L M$ model, which is generally taken as a formal model of Keynes's General Theory, will make this even clearer.

It is at least not immediately obvious how complexity enters the picture. The number of components in Keynes's picture is in fact a reduction relative to what one would expect: It turns out there can be meaningful economic models that completely disregard the fact that economies are in reality made up of hundreds of thousands of individual actors. Apparently, if one identifies the appropriate causal factors at the aggregate level, one can abstract away much of the "complexity" of an economy. Similarly, the number of interactions between components does not multiply in Keynes's description. There are two levels of description in play, but I assume that this by itself does not qualify a model for the complexity label. Perhaps there is some other sense of complexity which applies to Keynes's science - but Urchs's paper is scant help, since his definition of complexity is elusive.

\subsection{The ineffectiveness of monetary policy during the economic crisis}

Another example discussed by Urchs suggests, upon close consideration, the same story: component-level complexity giving way to simpler aggregate-level models. Urchs reminds us that during the economic crisis, a standard remedy for slowing economic growth has proved ineffective: lowering interest rates in order to stimulate economic output. Urchs quotes John Coates:

"Economists assume economic agents act rationally, and thus respond to price signals such as interest rates, the price of money. In the event of a market crash, so the thinking goes, central banks need only lower interest rates to stimulate the buying of risky assets, which

\footnotetext{
${ }^{3}$ Proponents of austerity would not, however, deny the savings/investment equality. Instead, they might argue that government investment would increase interest rates and so "crowd out" private sector investment. Or they might argue that increased government spending would be taken as a sign of higher government deficits in the future. This in turn would lead to an expectation of higher future corporate taxes, which would again induce companies in the present to reduce investment.
} 
now offer relatively more attractive returns compared to the low interest rates on Treasury bonds. But central banks have met with very limited success in arresting the downward momentum of a collapsing market. One possible reason for this failure could be that the chronically high levels of cortisol among the banking community have powerful cognitive effects." (page number not yet available)

Perhaps the supposed relationship between the monetary base, interest rates and economic output is, as Urchs writes, "like a compass that will work properly only if there is no wind" (page number not yet available)?

The invocation of cortisol levels is certainly in the spirit of Sandra Mitchell's arguments that most interesting phenomena will ultimately have to be understood at a number of interacting levels. Her main example is clinical depression, where we must expect a full understanding to include both molecular factors and the patient's social environment, among other things. Similarly, economists may have to learn to model the behavior of bankers not just in terms of rational responses to interest rates, but also in terms of cortisol-related psychological processes of individuals.

Urchs himself expresses some skepticism about hormone-based explanations in economics. However, he is correct in noting that if macroeconomists must begin to model the hormonal state of individual traders, then macroeconomic models will increase in complexity in a number of possible senses: The number of interacting parts will increase, as will the potential for interactions among the parts and the required number of levels of description.

However, it is far from certain that irrationality-inducing cortisol levels are needed to explain the ineffectiveness of monetary policy during the economic crisis ${ }^{4}$ Some macroeconomists would argue that the ineffectiveness of monetary policy during the crisis is explained by aggregate-level factors - the kind that customarily enter into macroeconomic analyses. In particular, they would point to the $I S-L M$ model, which is taken as a formal representation of Keynes's General Theory. I ask the reader to bear with me as I briefly introduce the $I S-L M$ model. On this basis, it will then be possible to argue that the $I S-L M$ model offers an analysis of the ineffectiveness of monetary policy during the economic crisis which is plausibly non-complex.

For a full presentation of the $I S-L M$ model, I refer the reader elsewhere ${ }^{5}$ The basic and familiar idea is that economic output in an economy is determined both by the market for goods and services and by the market for money. More specifically, the model tells us how the interplay between the two markets determines interest rates and economic output. In a typical presentation of the $I S-L M$ model (see figure 1), interest rates are indicated on the vertical axis and GDP is indicated on the horizontal axis. The $I S$ curve (for "investment-saving") represents the market for goods and services and the $L M$ curve (for "liquidity preference-money supply") represents the market for money.

\footnotetext{
${ }^{4}$ This is not a rejection of neuroeconomics (for a discussion, see Mäki 2010). My rather more modest argument is that the neurosciences may not be needed in the particular case discussed by Urchs.

${ }^{5}$ See for instance chapters 10 and 11 in the textbook by N. Gregory Mankiw (2002), and for a brief blog-sized overview see Paul Krugman (2011).
} 


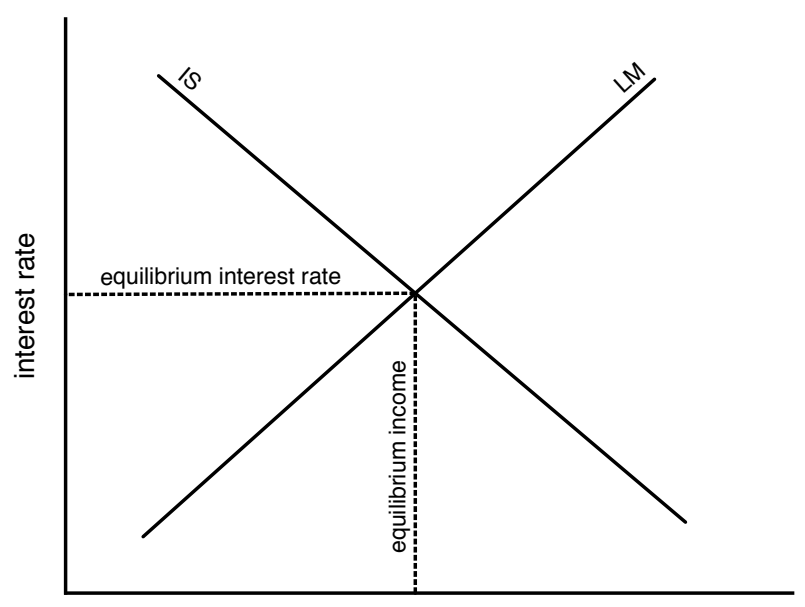

income, output, GDP

Fig. 1 The $I S-L M$ model after Mankiw (2002) and Krugman (2011). See text for explanations.

Let us look at the $I S$ curve first, where the interest rate is the independent variable and GDP is the dependent variable. Changes in the market for goods and services can increase or decrease economic output. Decreases in interest rates will make the financing of investments less costly, and so lower interest rates increase economic output (this is why the $I S$ curve is downward sloping). Several factors can shift the $I S$ curve. Increased government purchases will increase overall expenditures, overall income, and economic output. Similarly, a tax decrease will also expand expenditure and income. Both sorts of changes would shift the $I S$ curve to the right. Conversely, a decrease in government spending or a tax increase would shift the $I S$ curve to the left.

Let us now turn to the $L M$ curve, where GDP is the independent and interest rate the dependent variable. A higher GDP will mean higher demand for money, since more interactions requiring money take place, and so interest rates will be higher if GDP is higher (this is why the $L M$ curve is upward sloping). Again there are factors that can shift the $L M$ curve. Interest rate at any given GDP can be affected by changes in the amount of money available, that is, by the monetary policy of central banks. An increase in the monetary base will tend to reduce interest rates: it will shift the $L M$ curve to the right. The converse happens if the monetary base is reduced.

It is important to understand that the $I S$ and $L M$ curves represent possible equilibrium points in the market for goods and services and the market for money. Let's look at the market for goods and services first. If GDP were above the level compatible with a certain interest rate, this would mean that companies are producing more goods than are demanded by current investment. Hence, companies would accumulate inventory and in response decrease production, which would bring GDP in line with interest rates. Conversely, if GDP were below the level compatible with 
the interest rate, more goods would be demanded than produced, inventories would decline, and companies would increase production. This would again bring actual GDP in line with the interest rate. In the market for money, an equilibrium process is also at work. If interest rates were above equilibrium levels, individuals would try to convert more of their money into interest-bearing bank deposits or bonds, and this excess supply of money would cause banks and bond issuers to lower the interest rates they offer. Conversely, if the interest rate were below equilibrium, banks and bond issuers would offer higher interest rates to attract scarce money. The economy as a whole is at the point where both the market for goods and services and the market for money are in equilibrium: that is, at the intersection of the $I S$ and $L M$ curves.

Now how can the $I S$ - $L M$ model explain the ineffectiveness of monetary policy during the crisis? This is where I take it that there is controversy within the science of economics. One explanation on offer, defended forcefully by the Nobel Prize winner Paul Krugman, is that the economy in the crisis was in a so-called "liquidity trap" 6 The basic idea is that many individuals in the economic crisis suddenly found themselves in a position where they had a debt burden to reduce. This caused expenditures to go down drastically - it shifted the $I S$ curve far to the left, reducing interest rates and economic output. Central banks reacted to the slump in output by increasing the money supply (shifting the $L M$ curve to the right). In normal times, this would reduce interest rates and stimulate investment spending. However, since the shift in the $I S$ curve had already brought interest rates close to zero, a shift in the $L M$ curve could not affect them further, and so monetary policy had to remain ineffective. This situation is shown in figure 2

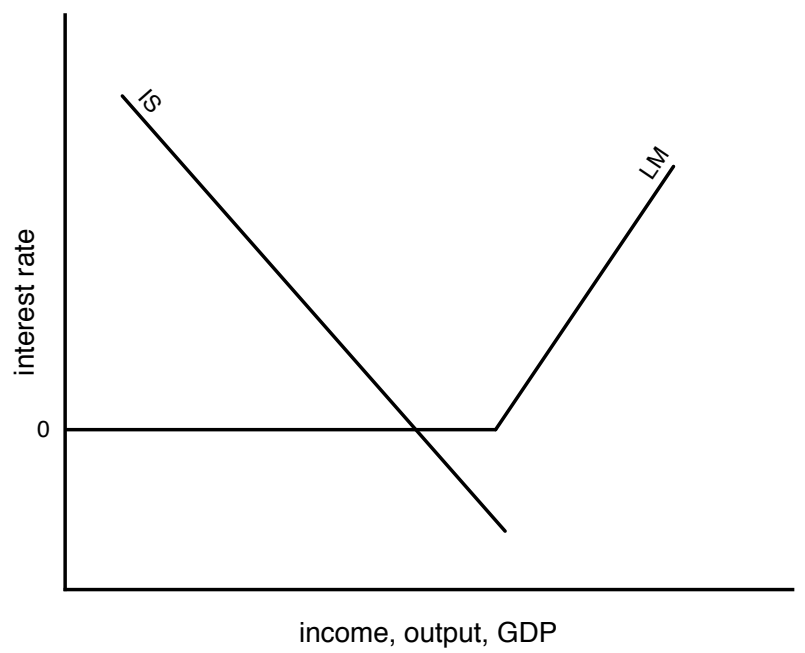

Fig. 2 The $I S$-LM model in a "liquidity trap" (after Krugman 2011). See text for explanations.

\footnotetext{
${ }^{6}$ See also Mankiw's discussion of the liquidity trap in his textbook (Mankiw. 2002, chapter 11.
} 
The liquidity trap offers an explanation for the failure of monetary policy during the great recession which impresses by its relative simplicity. It is not within my competence to say whether this explanation actually is correct. But if it is correct, then macroeconomic success was again achieved by modeling the correct aggregate factors and the correct causal relationships between them. And as far as I can tell, the $I S-L M$ model is not complex in the sense discussed here. Both in terms of entities and interactions, the model is relatively parsimonious.

We must ask, however, whether the explanation provided by the $I S-L M$ model is truly independent of an explanation which invokes, for instance, the cortisol level of individuals. Aren't neuroscientific factors simply what explains that the IS curve shifted far to the left - or in other words, isn't the $I S$ - $L M$ analysis a mere description of a process which Urchs (quoting Coates) wants to explain causally by appeal to cortisol levels?

In a trivial way, neuroscientific facts are certainly part of the complete causal story. The shift of the IS curve is explained by a reduction in overall planned expenditure in the economy, caused by many economic actors suddenly facing a debt burden. All of this must be realized at the individual and neuronal level - and not all individuals will face the same sort of debt, or react to it psychologically and neurally in the same way. So micro-level realizations of the aggregate-level fact of "a large decrease in planned expenditure" certainly exist and are multiply realized. But I presume that this would be largely uncontested.

The more pressing question is whether the cortisol-levels explanation is intended as complementary or alternative to the customary macroeconomic analysis. Returning to the first sentence of Urchs's quote from Coates, we read:

"Economists assume economic agents act rationally, and thus respond to price signals such as interest rates, the price of money." (page number not yet available, my emphasis)

Since economic agents during the crisis seemed not to react to price signals, cortisol levels are offered as an explanation of this irrationality. They are thus clearly intended as an alternative explanation: The neuroscientific facts are taken to explain something that on a customary analysis remains obscure. However, on the $I S-L M$ analysis economic agents were not behaving irrationally, and so there is nothing for the cortisol-levels hypothesis to explain! With interest rates having approached the zero lower bound, an increase in the monetary base could not have been expected to alter interest rates further - even if all economic agents were behaving rationally. Cortisol levels and other neuroscientific facts surely constitute part of the microlevel realization of macroeconomic states, but they are mere intermediate causes: the explanatory work is done by the aggregate-level theory.

Friends of complexity might accept the foregoing analysis but insist that the explanation of the ineffectiveness of monetary policy during the crisis is precisely what complexity is all about. Among Urchs's features of complexity is:

"The very mechanism which generates a system's behaviour is changing, leading thereby to the evolution of new forms of connections." (page number not yet available)

One might tell the story thus: In normal times, the economic system's behavior is such that an increase in the monetary base increases economic output. In the crisis, 
the mechanism generating this behavior changed, leading to unexpected new results. But I think it would be unwise to use the term "complexity" in case where we are simply dealing with misconceptions about the mechanisms operating in the system. The relevant macroeconomic model was perhaps not widely understood, but it is not particularly complex.

Urchs writes that standard models in the economic crisis were somewhat like a compass that only works if there is no storm. It is true that the expected relationship between expansion of the monetary base and economic output broke down during the crisis, but the actual compass - the $I S-L M$ model - may have weathered the storm successfully. The $I S-L M$ model is certainly more complex than the basic expectations about monetary policy and economic output, but it is still relatively simple.

It is of course possible to criticize the $I S-L M$ analysis from the point of view of complexity. For example, W. Brian Arthur (1999) argues that equilibrium analyses are generally in need of expansion. I am sympathetic to this. But the case for such expansions must rest on phenomena that the equilibrium analysis cannot explain. And if my account above is correct, then the ineffectiveness of monetary policy during the crisis of 2008 is not such a phenomenon.

To summarize, I remain skeptical that either Keynes's talk about the properties of parts and wholes or the ineffectiveness of monetary policy during the crisis offer particularly good examples of complexity. Macroeconomic success in both cases is not obviously dependent on an understanding of what Sandra Mitchell or Max Urchs would call complexity. To the contrary, it seems that the key was to find an aggregate-level description of the economy which could successfully handle the system's component-level diversity. All of this leaves open the possibility, of course, that other cases from economics do in fact necessitate complexity thinking.

\section{The "Renaissance Pact"}

Urchs claims that science and society entered, some four hundred years ago, into a "Renaissance pact" or "promise":

"We, the scientists, will work hard to uncover the most fundamental structures of the world. We will describe them in mathematical language in a Golden Book of Nature. Everyman receives a precise and perspicuous picture of reality that lays the foundation for technological progress. We will be rewarded for that." (page number not yet available)

He claims that the pact is now in need of revision because of complexity.

It is not clear how this Renaissance pact should be interpreted. Urchs paints the scientific revolution as a response to an earlier breakdown in the communication between science and society, largely because science was theoretical rather than applied. From this he develops the notion of a new relationship between science and society from the renaissance onward - the aforementioned pact or promise. Urchs does not refer to the historical literature to back up these claims. To the best of my knowledge, they are untenable. 
One difficulty of the proposal is that it may not even be a testable historical thesis. This is because it is hard to conceptualize. Pacts have signatories, and promises are made by someone to someone. Yet who would that be? Even if we take all early modern scientists to pursue roughly the goal stated above (to "uncover the most fundamental structures of the world"), which individuals or groups from society offered a reward in return? Was it because a reward was promised that science was professionalized and eventually publicly funded, some two centuries later? As a matter of historical scholarship, I do not know how this thesis can be made precise or plausible.

But I suspect that the idea must be taken metaphorically: Over the past four centuries, science has increasingly served society in a certain way, and now this may be changing. Leaving the problematic historical claims aside, Urchs may be saying that the epistemological goals of science may need to be adjusted.

Urchs seems to be thinking along the lines of Sandra Mitchell's chapter 5, which discusses policy in a world of complexity. On one conception, the task of science is to make definitive predictions about the consequences of particular courses of action (for instance, on whether anthropogenic greenhouse emissions will or won't cause radical climate change), and these predictions then allow us to act so as to achieve our desired outcomes. However, from a science of complexity we may not get definitive predictions, but only an analysis of different possible outcomes. Parts of the outcome space may show such sensitive dependence on initial conditions that no predictions are possible. Policy in turn may not be able to choose one outcome as a goal: We may have to settle for policy which is robust in the sense that it leads to acceptable outcomes in a variety of different scenarios, and our policy may in any case have to adapt itself as more is learned about the systems with which we are dealing.

I find these ideas by and large unobjectionable, and to the extend that Urchs is thinking about the same sorts of things, I agree with him. But we would have to think carefully about whether any of this leads to a change in the relationship between science and society. I rather suspect, for instance, that Mitchell gives us a somewhat caricatured view of the "predict and act" model on which science is supposed to have acted in the past. And the strength of the thesis clearly depends on describing current practice correctly: If the new principles urged by the friends of complexity are already part of science, then the new approach to prediction and policy may not differ much from business as usual 7

In summary, it is not entirely clear what Urchs's aims are in formulating the thesis of the "Renaissance promise". As a historical thesis it fails, and as a metaphor its precise content remains to be articulated.

\footnotetext{
${ }^{7}$ Another worrisome note is offered by a reviewer of Mitchell's book. Kristin Shrader-Frechette (2013) points out that some of Mitchell's phrases such as "flexible management", "continued investigation" and "learn by doing" can be weaponized by Washington lobbyists to mean toothless regulation, delayed action and science-blindness.
} 


\section{On the Function of Case Studies in Philosophy of Science}

Philosophy of science works best with a strong empirical component, and so the use of case studies from historical or contemporary science is necessary and welcome. But it is a challenge to choose the right cases for any given philosophical purpose. To illustrate the point, suppose we are interested in heuristics for the generation of novel scientific hypotheses, and part of our argument is to show that our philosophical proposal operates in a case study from actual science. It would surely tell us little to see that one or another method of theory generation applies to a trivial scientific discovery: It will not come as a surprise to anybody that some simple heuristics can illuminate successful but modest extrapolations from known and well confirmed theories. In order for our cases to test the value of the proposed heuristics, they must be scientific theories of acknowledged novelty and originality. In this case, hypotheses that led to a Nobel Prize are perhaps promising candidates. In general, we may say that we must challenge our philosophy with hard cases.

The problem of the choice of case studies is particularly acute in the complexity debate. One use for case studies is to show that we can solve certain problems only by being mindful of one feature of complexity or another - for example, by studying the interactions of a great many components, or by integrating causality at multiple levels of organization or in multiple domains of investigation. But of course this argument can only be made once at least some such problems are actually solved. Only when some results are in can we analyze them and show how complexity thinking was epistemologically fruitful.

Urchs's section on neuroscience, however, is a mere promissory note: Neuroscience may solve some or even many of its outstanding questions through methods that are more mindful of complexity. This is plausible, since the number of entities is known to be large and multiple levels of organization seem to be relevant. But little is accomplished by pointing to a subject which is at present insufficiently understood. Our insufficient understanding may stem from the fact that we have not been mindful of complexity - but we may also lack the right kind of mathematical methods, or perhaps the correct aggregate-level causal factors have not yet been identified (as was essential for Keynes's work). Without additional arguments for the use of complexity thinking, we do not learn much from neuroscience's outstanding questions beyond the fact that these questions exist.

A partial model for how to navigate this territory is Sandra Mitchell's Unsimple Truths (2009b). Discussing older concepts of emergence in her second chapter, Mitchell notes that philosophers in the 19th century spoke of emergence in the context of chemical properties (the fluidity of water, for instance) and biological properties (inheritance) which later received reductive explanations. Mitchell then argues for what she hopes will be a more useful new concept of emergence. By opening her discussion with such philosophical precursors, Mitchell to some extent diffuses the fears of readers like me: She knows that the number of phenomena that seem intractable by customary methods has decreased for centuries, and that simply pointing to an as yet ill-understood area of science is no argument for the necessity of new methods. What is required in addition is an argument for why the remaining 
unsolved questions are different. Similarly, Mitchell discusses the case of major depressive disorder in some detail to show how complexity thinking has been required for understanding it. One can argue about whether Mitchell is entirely successful in her project. In particular, I wished for a much more detailed treatment of the case study. But at least her plan of attack is exactly right.

In summary, while the use of case studies in philosophy of science is necessary and welcome, it is also difficult. Cases must be chosen such that a true test of a philosophical thesis is possible. I argued that this does not succeed in Urchs's section on neuroscience (the case) and complexity (the philosophical thesis).

\section{Conclusions}

Having titled my comments "confessions of a complexity skeptic", I conclude by stressing - call it a hedge, if you must - that I have considerable sympathy for the project of the friends of complexity. I wish the debate a long and healthy life. It is difficult to approach philosophy of science from the perspective of the biomedical sciences without suspecting that the notion of complexity may be both analytically tractable and useful. Complex systems may lead us to a more robust concept of emergence, or to a better understanding of causal inference in biological and social systems. So my position should probably be described as local skepticism: I have made explicit concrete problems faced by Urchs's discussion of complexity, and this leaves the door wide open for others to make the case for complexity more compelling. However, the objections raised in my discussion have some claim to generality. In order to argue for or against complexity, we will need to consider cases from actual science very closely, and to think hard about what they can and cannot tell us.

\section{References}

Arthur WB (1999) Complexity and the Economy. Science 284:107-109

Keynes JM (1973a) The General Theory of Employment, Interest and Money, The Collected Writings of John Maynard Keynes, vol VII. Macmillan

Keynes JM (1973b) Treatise on Probability, The Collected Writings of John Maynard Keynes, vol VIII. Macmillan

Krugman P (2011) IS-LMentary. URL http://krugman .blogs . nytimes . com/2011/10/09/is-lmentary/, accessed on April 16, 2013

Ladyman J, Lambert J, Wiesner K (2012) What is a complex system? European Journal for Philosophy of Science 3(1):33-67

Mäki U (2010) When economics meets neuroscience: hype and hope. Journal of Economic Methodology 17(2):107-117

Mankiw NG (2002) Macroeconomics, 5th edn. Worth Publishers 
Mitchell M (2009a) Complexity: A Guided Tour. Oxford University Press, USA

Mitchell SD (2009b) Unsimple Truths: Science, Complexity, and Policy. University of Chicago Press

Shrader-Frechette K (2013) Sandra D. Mitchell: Unsimple truths: Science, complexity, and policy. The British Journal for the Philosophy of Science 64(2):449-453 